\title{
Heterosis analysis and underlying molecular regulatory mechanism in a wide- compatible neo-tetraploid rice line with long panicles
}

Mohammed Abdullah Abdulraheem Ghaleb ${ }^{1,2,3 \dagger}$, Cong $\mathrm{Li}^{1,2,3 \dagger}$, Muhammad Qasim Shahid ${ }^{1,2,3+}$ (D) Hang Yu $\mathrm{u}^{1,2,3 \dagger}$,

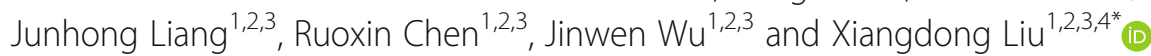

\begin{abstract}
Background: Neo-tetraploid rice, which is a new germplasm developed from autotetraploid rice, has a powerful biological and yield potential and could be used for commercial utilization. The length of panicle, as a part of rice panicle architecture, contributes greatly to high yield. However, little information about long panicle associated with heterosis or hybrid vigor is available in neo-tetraploid rice.

Results: In the present study, we developed a neo-tetraploid rice line, Huaduo 8 (H8), with long panicles and harboring wide-compatibility genes for pollen and embryo sac fertility. All the hybrids generated by $\mathrm{H} 8$ produced significant high-parent yield heterosis and displayed long panicles similar to H8. RNA-seq analysis detected a total of 4013, 7050, 6787 and 6195 differentially expressed genes uniquely belonging to $F_{1}$ and specifically (DEGFu-sp) associated with leaf, sheath, main panicle axis and spikelet in the two hybrids, respectively. Of these DEGFu-sp, 279 and 89 genes were involved in kinase and synthase, and 714 cloned genes, such as GW8, OsGA20ox1, Ghd8, GW6a, and LP1, were identified and validated by qRT-PCR. A total of 2925 known QTLs intervals, with an average of 1 100 genes per interval, were detected in both hybrids. Of these, 109 yield-related QTLs were associated with seven important traits in rice. Moreover, 1393 non-additive DEGs, including 766 up-regulated and 627 down-regulated, were detected in both hybrids. Importantly, eight up-regulated genes associated with panicle were detected in young panicles of the two hybrids compared to their parents by qRT-PCR. Re-sequencing analysis depicted that $L P$ (a gene controlling long panicle) sequence of $\mathrm{H} 8$ was different from many other neo-tetraploid rice and most of the diploid and autotetraploid lines. The qRT-PCR results showed that $L P$ was up-regulated in the hybrid compared to its parents at very young stage of panicle development.
\end{abstract}

Conclusions: These results suggested that $\mathrm{H} 8$ could overcome the intersubspecific autotetraploid hybrid rice sterility caused by embryo sac and pollen sterility loci. Notably, long panicles of $\mathrm{H} 8$ showed dominance phenomenon and played an important role in yield heterosis, which is a complex molecular mechanism. The neotetraploid rice is a useful germplasm to attain high yield of polyploid rice.

Keywords: Rice (Oryza sativa L.), Neo-tetraploid rice, Hybrid vigor, Panicle, Transcriptome

\footnotetext{
* Correspondence: xdliu@scau.edu.cn

${ }^{\dagger}$ Mohammed Abdullah Abdulraheem Ghaleb, Cong Li, Muhammad Qasim

Shahid and Hang Yu contributed equally to this work.

${ }^{1}$ State Key Laboratory for Conservation and Utilization of Subtropical

Agro-Bioresources, South China Agricultural University, Guangzhou 510642,

China

${ }^{2}$ Guangdong Provincial Key Laboratory of Plant Molecular Breeding, South

China Agricultural University, Guangzhou 510642, China

Full list of author information is available at the end of the article
}

(c) The Author(s). 2020 Open Access This article is distributed under the terms of the Creative Commons Attribution 4.0 International License (http://creativecommons.org/licenses/by/4.0/), which permits unrestricted use, distribution, and reproduction in any medium, provided you give appropriate credit to the original author(s) and the source, provide a link to the Creative Commons license, and indicate if changes were made. The Creative Commons Public Domain Dedication waiver (http://creativecommons.org/publicdomain/zero/1.0/) applies to the data made available in this article, unless otherwise stated. 


\section{Background}

Rice is one of the world's most important cereal grains [1]. Hybrid rice occupies more than $50 \%$ of the total rice area in China, and has a yield advantage of about 10$20 \%$ over inbred varieties [2]. However, with an increasing world population and gradually deteriorating environment, food security has become a major challenge, especially in Asia and Africa [3, 4]. During the last few years, rice production is stagnant due to intensification of crops and other biotic and abiotic factors. Therefore, it is of immense importance to develop high yielding rice cultivars resistant to various biotic and abiotic stresses.

Autotetraploid rice is a useful germplasm developed from diploid rice by chromosome doubling using colchicine treatment. Intersubspecific hybrids of autotetraploid rice have a powerful biological and yield potential, which may become a new way to breed rice in future [5-7]. However, low seed setting is the major hindrance in the use of autotetraploid rice at commercial level [8-13]. Polyploidy fortifies $F_{1}$ pollen sterility loci interactions, which causes meiosis abnormalities and produce high pollen sterility in autotetraploid rice hybrids that could be overcome by double pollen fertility neutral genes $\left(\mathrm{Sa}^{n}\right.$ and $\left.S b^{n}\right)[14,15]$. Consequently, how to create new tetraploid rice lines with normal fertility and to overcome the sterility of $\mathrm{F}_{1}$ hybrids is a key step to use the tetraploid rice. After years of unremitting efforts, our research group has successfully developed a new "autotetraploid rice lines" by selective breeding and crossing for successive generations. The new "autotetraploid rice" displayed high fertility (> 80\%) and high heterosis when crossed with other autotetraploid rice lines having low fertility [16-18]. Moreover, $\mathrm{F}_{2}$ and $\mathrm{F}_{3}$ populations also displayed high fertility and stable morphological traits like neo-Arabidopsis [16, 18, 19]. The new "autotetraploid rice" wasn't an allotetraploid rice; however, its chromosome behavior was nearly normal, which contributed to high fertility and harbors specific DNA mutations that were different from autotetraploid rice. Therefore, we defined new "autotetraploid rice" as neotetraploid rice [16].

RNA-seq-based transcriptome data enables to understand the role of differentially expressed genes associated with abiotic stress and pollen development in rice [20, 21]. Using RNA-Seq, significant progress has been made in understanding the expression patterns of genes during pollen development between diploid and autotetraploid rice over the last few years [12, 13, 22]. Furthermore, RNA-seq has also been widely used in the study of genetic variations in plants. The complexity of gene expression profiles associated with heterosis in different tissues had been revealed in various plants, such as rice $[16,17$, $23,24]$, tobacco [25], wheat [26, 27], rapeseed [28], and maize [29]. Transcriptome diversity between hybrid rice and their parents was analysed in various tissues during different development stages and specific differentially expressed genes related with heterosis were identified in rice [16, 17, 23, 30-32].

Length of panicle, as a part of rice panicle architecture, is an important agronomic trait of rice, which significantly affects the rice yield. Many genes related to diploid rice panicle architecture have been identified or cloned, such as OsSPL18 [33], IPA1 /OsSPL14 [34], Ghd7 [35], DEP1 [36], LP [37], Gn1a [38], GW8/ OsSPL16 [39], and SPL [40]. OsSPL18 had the same gene structure and expression pattern as that of GW8/ OSSPL16, and it regulates the expression level of DEP1 [33]. IPA1/OsSPL14 is regulated by OsmiR156 [34], and $D S T$ enhanced grain production by controlling the expression patterns of Gn1a/OsCKX2 [41]. FRIZZLE PAN$\operatorname{ICLE}(F Z P)$ is a major negative regulator of RFL/APO2 and determined the transition from panicle branching to spikelet formation [42]. However, little information is available about long panicle in neo-tetraploid and autotetraploid rice.

In this study, we reported the breeding procedure of a neo-tetraploid rice with long panicles, harboring widecompatibility genes, which could overcome $\mathrm{F}_{1}$ sterility. This study was planned to evaluate the heterosis of neotetraploid rice crossed with different autotetraploid rice lines, and to analyse molecular aspects of heterosis using RNA-seq-based transcriptome and re-sequencing analysis. Moreover, the expression patterns of important genes were validated by qRT-PCR. Our study will provide new germplasm for polyploid rice breeding and help us to understand the variations in gene expressions associated with heterosis and long panicle between $\mathrm{F}_{1}$ hybrids and their parents.

\section{Results}

Development of neo-tetraploid rice with long panicle and its genotype at $F_{1}$ pollen sterility loci

In order to improve the panicle length of neo-tetraploid rice, an indica autotetraploid rice line, Linglun- $4 x$, with an average of $27.65 \mathrm{~cm}$ long panicle and harboring $S_{5}{ }^{n}$, was used as maternal to cross with a japonica autotetraploid rice line, L202-4x, with an average panicle length of $24.25 \mathrm{~cm}$ and harboring $S_{5}{ }^{n}$, in 2004. The $F_{1}$ generation was continuously self-crossed until $\mathrm{F}_{16}$, and one line with $30 \mathrm{~cm}$ long panicles and $60 \%$ seed set was developed in $2013\left(\mathrm{~F}_{17}\right)$. We planted that line continuously and developed a new line with long panicles from $\mathrm{F}_{18}$ to $\mathrm{F}_{20}$ generations. A neo-tetraploid rice line with $35 \mathrm{~cm}$ long main panicle was developed and named as "Huaduo 8” in 2015 (Figure S1a; Figure S1c). Huaduo 8 (H8) exhibited long panicles with narrowly distributed primary and secondary branches (Fig. 1; Figure S1b), and 

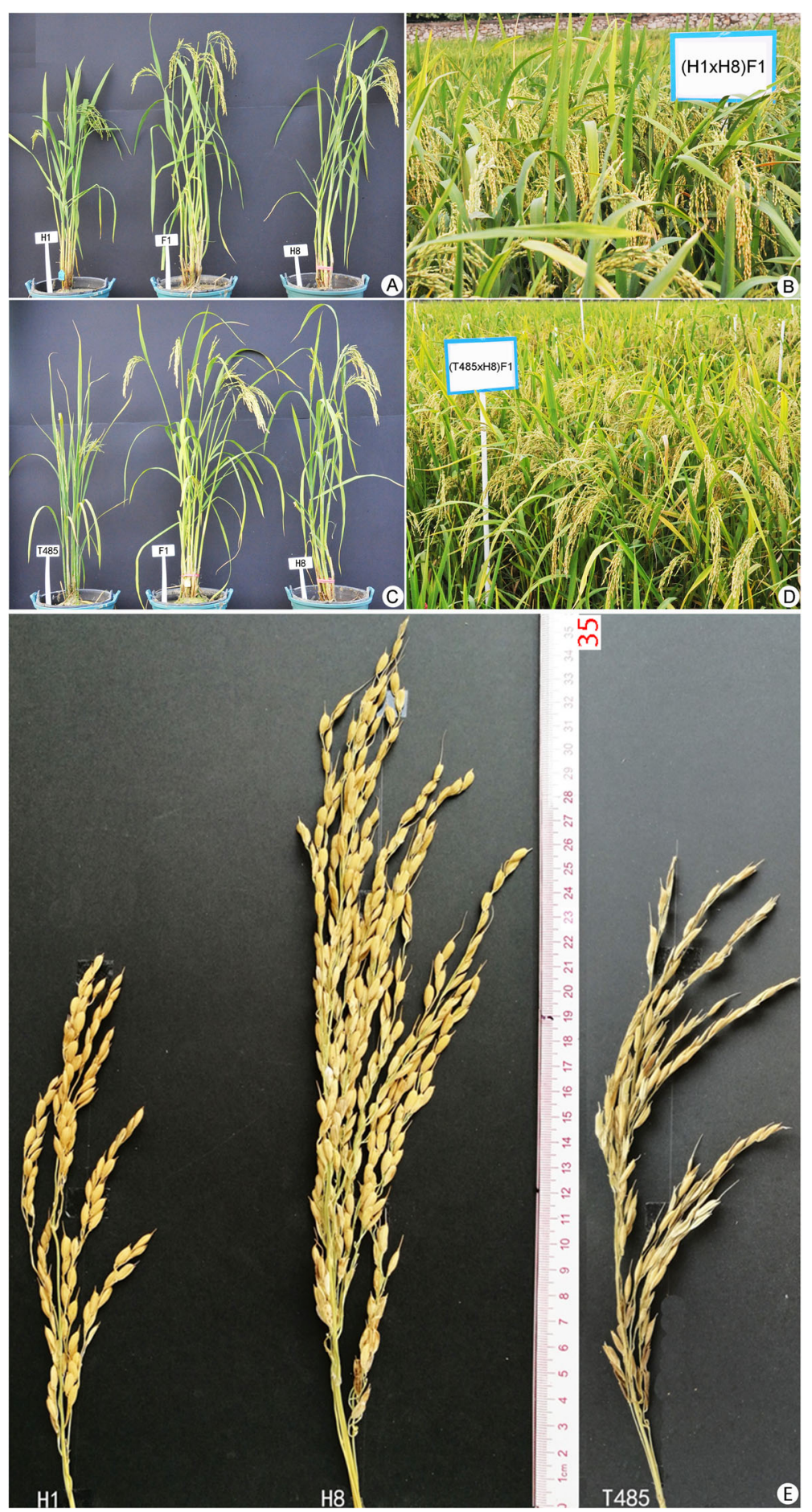

Fig. 1 Morphological characteristics of the parents and two hybrids. a, c: Plant appearance of parents and two $\mathrm{F}_{1}$ hybrids $(\mathrm{H} 1 \times \mathrm{H} 8$ and T485 $\times$ H8); b, d: Performance of the two hybrids in the field (maturity stage); e: Panicles of H1, H8 and T485. T485, H1and H8 indicate Huanghuazhan-4x, Huaduo 1 and Huaduo 8, respectively

displayed high stability in $\mathrm{F}_{3}$ to $\mathrm{F}_{5}$ generations, like neotetraploid Arabidopsis (Figure S1c).

Since our previous study revealed that interactions at $F_{1}$ pollen sterility loci, $S a, S b$ and $S c$ play key role in autotetraploid rice hybrid sterility, the genotypes of $\mathrm{H} 8$ and other parental lines at the $S-a, S-b$, and $S$-c loci were detected using closely linked molecular makers. The results revealed that $\mathrm{H} 8$ and other parental lines had 
different alleles at three loci, suggesting that hybrids exhibited different pollen sterility loci interactions at these loci. Moreover, the genotype of all materials at $S_{5}$ locus was also detected using $S_{5}$ functional molecular marker and the results indicated that $\mathrm{H} 8$ and 13 other parents contained $S_{5}{ }^{n}$ gene (Fig. 2; Additional file 1: Figure S2; Additional file 2: Table S1). These results suggested that $\mathrm{H} 8$ is a wide-compatibility germplasm of neo-tetraploid rice.

\section{Hybrid vigor analysis of the neo-tetraploid rice with long panicle}

Here, a total of 14 hybrids, including nine hybrids that were developed by crossing $\mathrm{H} 8$ with autotetraploid rice lines (i.e. four japonica and five indica lines), and five from crossing with other neo-tetraploid rice lines with high fertility (70.63\%) (Additional file 2: Table S2). For panicle length, six hybrids showed positive significant high parent heterosis $(\mathrm{HPH})$, and $\mathrm{T} 49 \times \mathrm{H} 8$ depicted the highest $\mathrm{HPH}$. Notably, all the hybrids displayed long panicles, and $\mathrm{T} 49 \times \mathrm{H} 8$ exhibited the largest panicle length i.e. $37.61 \mathrm{~cm}$ (Additional file 1: Figure S1b and S1c; Additional file 2: Table S3). Notably, yield and yield components of these hybrids displayed significant improvement, especially seed setting, grain yield per plant, and filled grains per plant. Of these traits, the mean value of seed setting was higher than $77.04 \%$, grain yield per plant was higher than $26.50 \mathrm{~g}$, and filled grains per plant was higher than 650 in all hybrids (Additional file 2: Table S3).

All the hybrids exhibited significant positive mid parent heterosis $(\mathrm{MPH})$ for all traits except the number of panicles per plant, and significant positive $\mathrm{HPH}$ for number of grains per plant and 1000-grain weight in both seasons. Three $\mathrm{F}_{1}$ hybrids displayed good performance for important agronomic traits, i.e. T45 $\times \mathrm{H} 8$ showed significant positive $\mathrm{HPH}$ and $\mathrm{MPH}$ for all traits except HPH for 1000-grain weight, T419 $\times$ H8 displayed significant positive $\mathrm{HPH}$ and $\mathrm{MPH}$ for all traits except the number of panicles per plant, and $\mathrm{T} 49 \times \mathrm{H} 8$ exhibited significant positive HPH for all traits except the number of panicles per plant and seed setting, and also yielded the highest $\mathrm{HPH}$ and $\mathrm{MPH}$ for important traits, including panicle length, filled grains per plant and grain yield per plant (Additional file 2: Table S2). The yieldrelated traits, such as seed setting, grain yield per plant, and filled grains per plant improved significantly in the hybrids produced by crossing $\mathrm{H} 8$ with neo-tetraploid rice compared to the hybrids developed by crossing $\mathrm{H} 8$ with autotetraploid rice (Additional file 2: Table S3).

Among the 14 hybrids, we selected two hybrids, $\mathrm{T} 485 \times \mathrm{H} 8$ and $\mathrm{H} 1 \times \mathrm{H} 8$, to analyze $\mathrm{F}_{1}$ yield-related heterosis by transcriptome analysis. T485 is an autotetraploid rice line with low fertility (33.35\%) and $\mathrm{H} 1$ is a
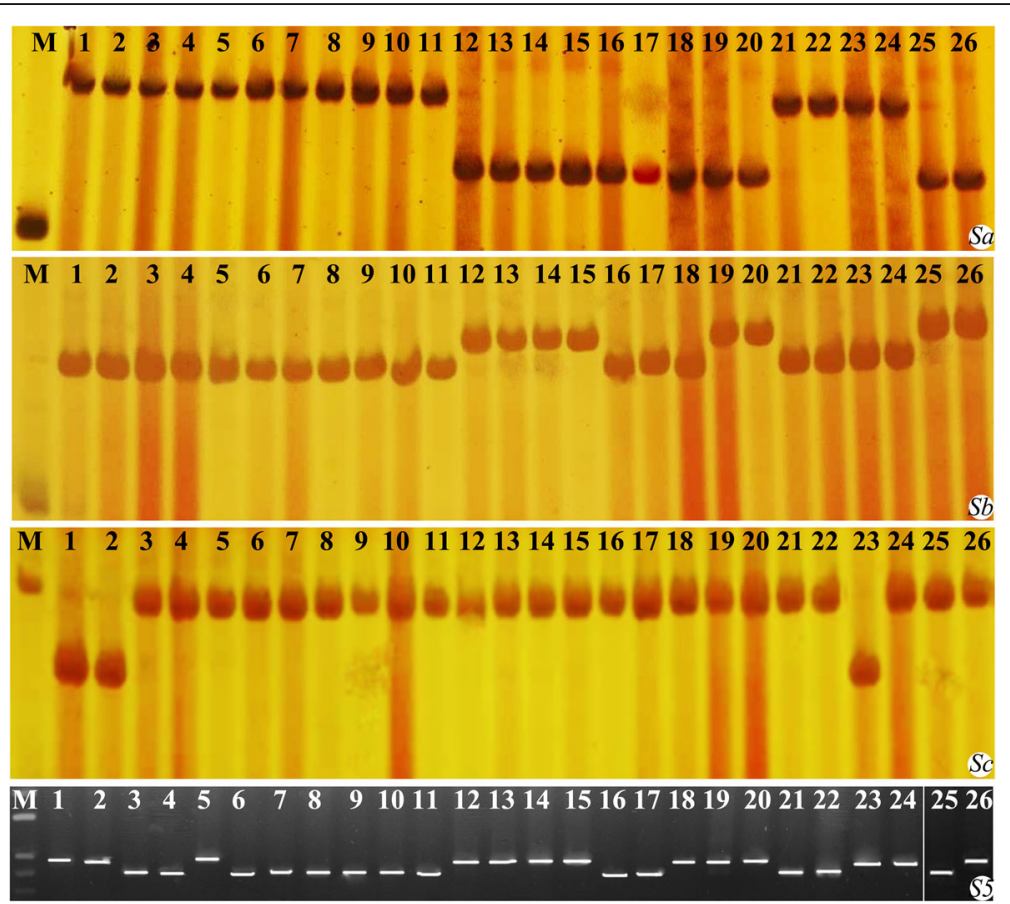

Fig. 2 Genotypes of parental lines at pollen sterility loci (Sa, Sb and Sc) and S5 locus detected by molecular markers. First image indicates the genotypes at Sa locus, followed by (upper to lower) Sb, Sc and S5 locus. M indicates DNA ladder, lanes 1-4 indicate control cultivars (typical indica and japonica cultivars), while lanes 5-26 indicate neo-tetraploid/autotetraploid rice lines (see the name of materials in Additional file 2: Table S1). Lanes 25 and 26 in S5 were taken from another gel 
neo-tetraploid rice line with high fertility (65.3\%). The two hybrids showed high positive $\mathrm{MPH}$ and $\mathrm{HPH}$ for important yield-related traits, including seed setting, grain yield per plant, 1000-grain weight, and number of filled grains per plant. The yield of two hybrids was significantly higher than their parents (Additional file 2: Table S3). Moreover, the seed setting was high in $F_{2}$ of $\mathrm{H} 1 \times \mathrm{H} 8$, with an average of $71.35 \%$. Interestingly, $\mathrm{H} 1 \times$ $\mathrm{H} 8$ showed better performance than $\mathrm{T} 485 \times \mathrm{H} 8$ in all traits except panicle length (Table 1).

\section{Transcriptome analysis of $F_{1}$ hybrids and their parents}

More than 5464 million clean reads were obtained from the two $\mathrm{F}_{1}$ s, including $\mathrm{T} 485 \times \mathrm{H} 8$ and $\mathrm{H} 1 \times \mathrm{H} 8$, and their parents by RNA-seq of eight tissues (Additional file 2: Table S4a, b). We aligned these clean reads against the Nipponbare reference genome (MSU 7.0), and obtained an average of $95.11 \%$ annotated transcripts of the reference genome and $66.23 \%$ unique mapped reads. The correlation coefficient was more than 0.8 that displayed a significant correlation between three biological replicates of transcriptome data in the hybrids and their parents. We used eight pairs of primers to validate the expression levels of 32 samples by qRT-PCR, and the results demonstrated that the differential expression levels of eight genes were consistent with the transcriptome data (Additional file 1: Figure S3). Hierarchical cluster analysis revealed that most of the differentially expressed genes in $F_{1}$ were more close to those in $\mathrm{H} 1$ (Additional file 1: Figure S4), suggesting that $\mathrm{H} 1$ contributed greatly to the high fertility and yield-related traits in the hybrid compared to other parent, T485.

\section{Detection of differentially expressed genes (DEGs) from different tissues and gene ontology (GO) enrichment analysis}

A total of 150,377 DEGs, including 76,926 from $\mathrm{H} 1 \times \mathrm{H} 8$ and 73,451 from $\mathrm{T} 485 \times \mathrm{H} 8$, were detected from eight tissues, i.e. flag leaf, leaf sheath, main panicle axis and spikelet of two hybrids and their parents before flowering and 5 days after flowering, respectively. The DEGs were ranged from 857 to 8489 between two parents and $\mathrm{F}_{1}$ compared to its parents (Additional file 2: Table S5, S6).

The specific DEGs that were uniquely associated with $F_{1}$ hybrid compared to parents (DEGFu-sp) and could elaborate the phenotypic variations between $F_{1}$ hybrid and its parents $[16,23]$; so we focused on the DEGFu-sp to detect the genes related to heterosis. In total, 24,045 DEGFu-sp genes were identified in the two hybrids. Among DEGFu-sp, 4013, 7050, 6787 and 6195 were specifically associated with flag leaf, leaf sheath, main panicle axis and spikelet in the two hybrids, respectively (Table 2; Additional file 2: Table S7).

Gene ontology (GO) enrichment analysis revealed remarkable differences in the prominent functional categorization of genes in the eight tissues before and 5 days after flowering (Additional file 1: Figure S5; Additional File 2: Table S8a-c;). We identified 151 prominent terms in the biological process category, 61 in the molecular function category and 55 prominent terms in the cellular component category associated with DEGFusp to eight tissues (Table 3). Since two $F_{1}$ hybrids (i.e. $\mathrm{T} 485 \times \mathrm{H} 8$ and $\mathrm{H} 1 \times \mathrm{H} 8$ ) were developed using neo-tetraploid rice line with long panicle to analyze the yield-related heterosis, we focused on the specific common genes from DEGFu-sp and their prominent functional categories. A total of 280 DEGFu-sp with specific common elements, in which 20 prominent GO categories, such as GO:0045449 (regulation of transcription), GO:0060255 (regulation of macromolecule metabolic process), and GO:0003700 (transcription factor activity), were detected in the leaf sheath of both hybrids that was collected 5 days after flowering. In total, 196 DEGFu-sp with specific common elements, in which 21 prominent GO categories, including GO: 0043687 (post-translational protein modification), GO: 0006464 (protein modification process), GO: 0043412 (macromolecule modification), were identified in main panicle axis of both hybrids 5 days after flowering (Additional file 2: Table S8d).

Table 1 Agronomic traits of $F_{1}$ hybrids and their parents during two seasons

\begin{tabular}{|c|c|c|c|c|c|}
\hline \multirow[t]{2}{*}{ Traits } & \multicolumn{3}{|c|}{ Parents (Mean \pm SD) } & \multicolumn{2}{|c|}{$\mathrm{F}_{1}$ hybrids (Mean $\pm \mathrm{SD}$ ) } \\
\hline & $\mathrm{T} 485$ & $\mathrm{H} 1$ & $\mathrm{H} 8$ & $\overline{\mathrm{T} 485 \times \mathrm{H} 8}$ & $\mathrm{H} 1 \times \mathrm{H} 8$ \\
\hline Plant height $(\mathrm{cm})$ & $90.78 \pm 0.25$ & $101.39 \pm 1.63$ & $137.28 \pm 3.60$ & $132.28 \pm 2.49$ & $144.53 \pm 1.11$ \\
\hline No. of panicles per plant & $4.78 \pm 0.54$ & $5.45 \pm 0.98$ & $3.11 \pm 0.42$ & $3.77 \pm 0.31$ & $4.67 \pm 0.40$ \\
\hline Panicle length (cm) & $25.28 \pm 0.87$ & $20.72 \pm 0.55$ & $28.65 \pm 0.26$ & $28.44 \pm 1.12$ & $28.44 \pm 1.13$ \\
\hline Filled grains per plant & $153.39 \pm 40.13$ & $252.73 \pm 63.35$ & $308.72 \pm 29.09$ & $505.33 \pm 56.11$ & $589.10 \pm 42.79$ \\
\hline Grain yield per plant (g) & $5.14 \pm 1.16$ & $8.88 \pm 2.13$ & $10.89 \pm 0.75$ & $18.72 \pm 1.94$ & $23.18 \pm 1.50$ \\
\hline 1000-grain weight (g) & $34.68 \pm 2.98$ & $35.51 \pm 0.22$ & $35.35 \pm 1.15$ & $37.21 \pm 0.71$ & $39.55 \pm 0.62$ \\
\hline Seed setting (\%) & $33.35 \pm 4.53$ & $65.30 \pm 3.65$ & $55.82 \pm 6.19$ & $75.16 \pm 2.25$ & $77.04 \pm 3.80$ \\
\hline
\end{tabular}

T485, H1and H8 indicate Huanghuazhan-4x, Huaduo 1 and Huaduo 8, respectively 
Table 2 Differentially expressed genes (DEGs) in eight tissues of two hybrids and their parents

\begin{tabular}{|c|c|c|c|c|c|}
\hline $\mathrm{F}_{1}$ Hybrids & Tissues & DEG2P & DEGP1 & DEGP2 & DEGFu-spa \\
\hline \multirow[t]{9}{*}{$\mathrm{H} 1 \times \mathrm{H} 8$} & $0-L$ & 6257 & 1465 & 4874 & 1162 \\
\hline & $0-S$ & 4716 & 1342 & 3730 & 1408 \\
\hline & $0-P$ & 2409 & 1534 & 2205 & 1548 \\
\hline & $0-Z$ & 3615 & 995 & 2745 & 1151 \\
\hline & $5-L$ & 2120 & 1131 & 857 & 521 \\
\hline & $5-S$ & 4503 & 3813 & 3972 & 3020 \\
\hline & $5-P$ & 8489 & 984 & 6049 & 1137 \\
\hline & $5-Z$ & 3602 & 1665 & 3854 & 1903 \\
\hline & Total & 35,711 & 12,929 & 28,286 & 11,850 \\
\hline \multirow[t]{9}{*}{$\mathrm{T} 485 \times \mathrm{H} 8$} & $0-L$ & 6374 & 5082 & 1785 & 1568 \\
\hline & $0-S$ & 6309 & 4131 & 1485 & 1232 \\
\hline & $0-P$ & 3173 & 1539 & 1696 & 961 \\
\hline & $0-Z$ & 4872 & 1849 & 3707 & 1591 \\
\hline & $5-\mathrm{L}$ & 2471 & 1506 & 1046 & 762 \\
\hline & $5-S$ & 3328 & 1358 & 2605 & 1390 \\
\hline & $5-P$ & 3882 & 2902 & 4320 & 3141 \\
\hline & $5-Z$ & 3364 & 1603 & 3064 & 1550 \\
\hline & Total & 33,773 & 19,970 & 19,708 & 12,195 \\
\hline
\end{tabular}

T485, $\mathrm{H} 1$ and $\mathrm{H} 8$ indicate Huanghuazhan-4x, Huaduo 1 and Huaduo 8 , respectively

0-L, Flag Leaf; 0-S, Leaf sheath; 0-P, Spikelet; 0-Z, Main panicle axis before flowering; $5-L$, Flag leaf; $5-S$, Leaf sheath; 5-P, Spikelet; $5-Z$, Main panicle axis 5 days after flowering; DEGFu-sp ${ }^{\mathrm{a}}$ : Differentially expressed genes uniquely belonging to $F_{1}$ compared to parents (DEGFu-sp) associated with flag leaf, leaf sheath, spikelet and main panicle axis in the two hybrids before and 5 days after flowering

KEGG analysis revealed a total of 19 and 44 pathways associated with the DEGFu-sp in the two hybrids. Overall, 15 pathways were common in both hybrids, including STARCH and SUCROSE METABOLISM, PHOTOSYNTHESIS, PLANT-PATHOGEN INTERACTION, and CARBON FIXATION IN PHOTOSYNTHETIC ORGANISMS (Additional file 2: Table S8e).

\section{Functional analysis of DEGs associated with heterosis in different tissues}

Since the heterosis was involved in all biological traits of rice hybrids, and the most important traits were grain

Table 3 The prominent functional categorization of differentially expressed genes uniquely belonging to $F_{1}$ compared to parents (DEGFu-sp) associated with different plant tissues

\begin{tabular}{llllllllll}
\hline $\mathrm{F}_{1}$ hybrids & $0-\mathrm{L}$ & $0-\mathrm{S}$ & $0-\mathrm{P}$ & $0-\mathrm{Z}$ & $5-\mathrm{L}$ & $5-\mathrm{S}$ & $5-\mathrm{P}$ & $5-\mathrm{Z}$ & Total \\
\hline $\mathrm{H} 1 \times \mathrm{H} 8$ & 32 & 22 & 46 & 21 & 12 & 40 & 9 & 38 & 220 \\
T485 $\times \mathrm{H} 8$ & 67 & 12 & 24 & 65 & 47 & 41 & 83 & 32 & 371 \\
Total & 97 & 34 & 70 & 86 & 59 & 81 & 92 & 70 & 591 \\
\hline
\end{tabular}

T485, H1and $\mathrm{H} 8$ indicate Huanghuazhan-4x, Huaduo 1 and Huaduo 8 , respectively

0-L, Flag Leaf; 0-S, Leaf sheath; 0-P, Spikelet; 0-Z, Main panicle axis before flowering; 5-L, Flag leaf; 5-S, Leaf sheath; 5-P, Spikelet; 5-Z, Main panicle axis 5 days after flowering yield and resistance, we analyzed the genes associated with kinase and synthase, including protein kinase, starch biosynthesis and their related genes [23, 43]. Of the DEGFu-sp to the two hybrids, 279 and 89 genes were involved in kinase and synthase, respectively (Additional file 3: Table S9a, S9b; Table 10Se and 10Sf). Of these 279 genes associated with kinase, 15 genes were annotated as receptor protein kinase and 164 protein kinase, such as S-locus lectin protein kinase family protein, and OsWAK38-OsWAK receptor-like protein kinase (Additional file 3: Table S9a). Among 89 genes annotated as synthase, 16 genes were encoded as cellulose synthase, 10 for ATP synthase and 7 for phosphate synthase (Additional file 3: Table S9b). Moreover, 22 genes encoding NBS-LRR disease resistance protein or LRR receptor-like protein kinase and 76 transcription factors (TFs) were detected in the DEGFu-sp to both hybrids (Additional file 3: Table S9c, 9d). Of these, 21 genes were different from super hybrid diploid rice LYP9 [23] and 11 were the same as those in $\mathrm{F}_{1}$ hybrid $(\mathrm{T} 449 \times \mathrm{H} 1)$ [17], and $71 \mathrm{TFs}$ were different from super hybrid diploid rice LYP9 [23] and 29 were the same as those in $F_{1}$ hybrid $(\mathrm{T} 449 \times \mathrm{H} 1)$ [17]. Moreover, we compared with the data of cloned genes (https://funricegenes.github.io/), and a total of 714 common cloned genes were detected in the DEGFu-sp genes of the two hybrids (Additional file 3: Table S9e; Table 10Se and 10Sf). These genes could be divided into four groups, including morphological traits-related genes (at least 38 genes), physiological traits-related genes (at least 33 genes), resistance or tolerance-related genes (at least 66 genes) (Additional file 3: Table S9e) and other genes (577 genes). Among the morphological traits-related genes, some important traits related genes, such as grain number $(G n 1 a)$, and semi-dwarf $(s d 1)$ were detected. Four genes associated with eating quality were also identified in the physiological traits-related genes. Of the resistance or tolerance-related genes, 5 bacterial blight resistance genes, 9 blast resistance, 5 cold tolerance, 10 drought tolerance, and 9 salinity tolerance genes were identified (Additional file 3: Table S9e). Then, we compared the DEGFu-sp genes of the two hybrids with the genes associated with heterosis in diploid hybrid rice [44], and detected important genes, including NAL1, qGW8, OsGA20ox1, Ghd8, GW6a, LP1, and EUI1, $i$-sd$1(t)$ (elongated uppermost internode), sd1, OsGA20ox2 and qSD1-2 (dee-geo-woo-gen dwarf), $H d 3 a$ and $F T$ (heading date), DEP1, DN1, qPE9-1 and qNGR9 (DENSE PANICLE), and OsWRKY71.

\section{Mapping of DEGFu-sp in known quantitative trait loci (QTLs)}

The DEGFu-sp to two hybrids were used to map 8216 rice QTLs containing 236 traits (items) in the rice 
Gramene database (http://qtaro.abr.affrc.go.jp/), and the yield-related QTLs were analyzed. A total of 2925 QTLs intervals, with an average of 1 100 genes per interval, were identified, and 975 were common in both hybrids (Additional file 3: Table S10a,10b). Among the DEGFusp-related common QTLs, 109 rice yield-related QTLs associated with seven traits, including total biomass yield, biomass yield, number of filled grains, total of number grains, number of panicles, seed set and 1000grain weight, were detected. Many QTLs are well characterized, including seed set (AQCB017, AQCB018, AQGH011, AQGH028, AQBK049, AQBK050, AQED063, CQAS35 and CQB14), 1000-grain weight (AQAI071, AQAI076 and CQB16), and number of filled grains (AQCY010, AQCY030, AQCY041, AQCY055, AQCY061, AQCY089, AQCY100, AQCY109, AQCY111 and AQCY115) (Fig. 3; Additional file 3: Table S10b, S10c). A total of 15, 9, 10, 7, 11, 22, 1, 7, 2, 7, 10 and 8 common QTLs were detected on chromosome 1, 2, 3, 4, 5, 6, 8, 9, 10, 11 and 12, respectively (Fig. 3). We checked the functional annotations of the common QTL-related DEGFu-sp, and some of them showed potential association between DEGFu-sp and QTLs, for example relationship between JMJ706 (LOC_Os10g42690, H3K9 demethylase), OsClpB-m (LOC_OsO2g08490, ATPase) and AQCB018, AQED063 for seed set, respectively. Alpha amylase (LOC_Os05g32710) and CQB16 for 1000-grain weight, and OsLpa1(LOC_Os02g57400, low phytic acid 1) and AQGI200 for total biomass yield.
Moreover, we compared the DEGFu-sp-related QTLs data with two $F_{1}$ hybrids of neo-tetraploid rice T449 $\times$ $\mathrm{H} 1$ [17] and T452 $\times \mathrm{H} 3$ [16]. A total of 48 QTLs were common among the present and previous studies, including two were associated with 1000-grain weight (AQAI071 and CQB16), three with seed set (AQGH011, AQGH028 and CQB14), and 13 with number of panicles (Additional file 1: Figure S6; Additional file 3: Table S10d). Then, we compared the DEGFu-sp (DGHPU)-related QTLs data with super hybrid diploid rice LYP9 [23], and detected 57 different QTLs, including four associated with seed set (AQGH011, AQGH028, AQCB017 and AQED063), 15 with biomass yield, 14 with number of panicles and 24 with number of grains (Additional file 3: Table S10c).

\section{Non-additive gene expressions in $\mathrm{F}_{1}$ hybrids}

The DEGFu-sp could be divided into two types, i.e. additive and non-additive genes, which contributed by each allele from both parents and that deviates from the midparent value, respectively [16, 23]. A total of 1393 nonadditive DEGs, 766 up-regulated and 627 downregulated, were detected in both hybrids, including 166 , 362, 516 and 349 in leaf, sheath, panicle branches and main axis of panicles before and 5 days after flowering, respectively (Table 4; Additional file 4: Table S11a,b). We compared all the non-additive DEGs with the cloned genes data of rice, and found 13 genes with known functions in rice. Among 766 non-additive up-regulated

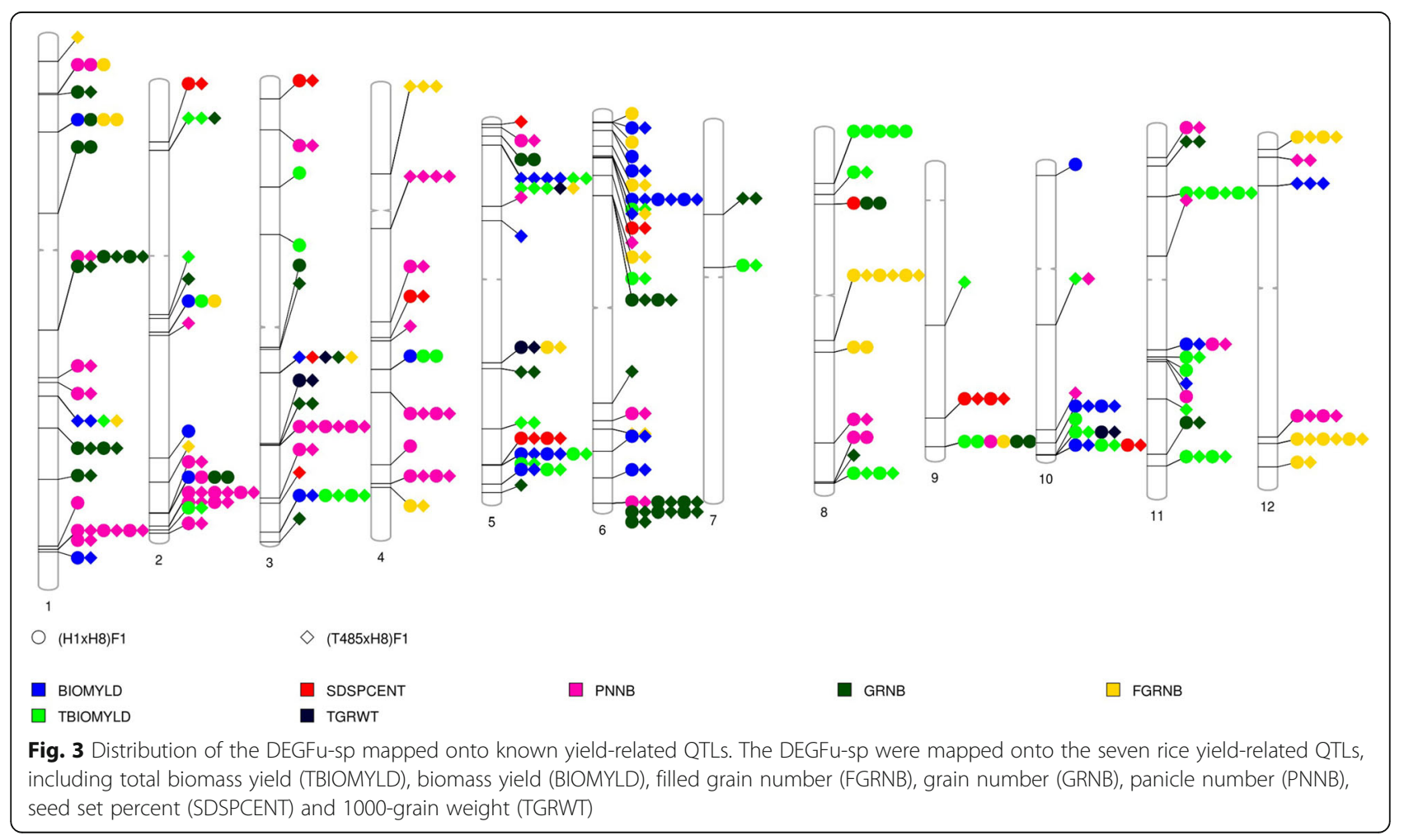


genes, four genes i.e. LOC_Os05g51610, LOC_ Os12g05709, LOC_Os09g11490 and LOC_Os11g28184 were found be common in leaf before fertilization in both hybrids. Twenty-nine genes were identified in main panicle axis before fertilization, 21 in spikelet after fertilization, one in flag leaf after fertilization, ten and five common genes in leaf sheath and main panicle axis were detected after fertilization in both hybrids, respectively (Additional file 4: Table S11c, d).

Notably, $\mathrm{H} 1 \times \mathrm{H} 8$ ( $\mathrm{F}_{1}$ hybrid) showed better performance than $\mathrm{T} 485 \times \mathrm{H} 8$, so we compared the non-additive DEGs overlapping with the cloned genes in both hybrids, and detected seven (LOC_OsO2g12350, LOC_ Os03g17350, LOC_Os10g42750, LOC_Os08g41940, LOC_ Os10g03400, LOC_Os04g46940 and LOC_Os04g57830) and two genes (LOC_OsO3gO6654 and LOC_ Os03g43990) specifically associated with $\mathrm{H} 1 \times \mathrm{H} 8$ and $\mathrm{T} 485 \times \mathrm{H} 8$, respectively. Moreover, two genes, i.e. $L O C_{-}$ Os12g18360 (Pi-ta) and LOC_OsO3g51970 (growth regulating factor), which regulated by Osa-miR396, were found to be common in two hybrids (Additional file 4: Table S11c, d).

\section{Genome-wide DNA variations in the neo-tetraploid rice with large panicle}

A total of 2,082,268 SNPs and InDels were detected in the neo-tetraploid rice with large panicle (H8) compared with a neo-tetraploid rice with short panicle $(\mathrm{H} 1)$, in which 82,319 homologous mutants associated with 15, 146 genes were detected in $\mathrm{H} 8$ compared to $\mathrm{H} 1$. We compared all the mutant genes with the functionally characterized genes of rice, and 257 genes were found with known functions in rice (Additional file 4: Table S12a). In total, 2,953,864 SNPs and InDels were detected in the neo-tetraploid rice with large panicle (H8) compared to the autotetraploid rice (T485). A total of 131, 112 homologous mutants associated with 24,777 genes were detected in H8 compared with T485, and 191

Table 4 Non-additive differentially expressed genes (NDEGs) and number of differentially expressed genes uniquely associated with $F_{1}$ (DEGFu-sp)

\begin{tabular}{lllllllll}
\hline$F_{1}$ Hybrids & $0-\mathrm{L}$ & $0-S$ & $0-P$ & $0-Z$ & $5-\mathrm{L}$ & $5-\mathrm{S}$ & $5-\mathrm{P}$ & $5-\mathrm{Z}$ \\
\hline $\mathrm{H} 1 \times \mathrm{H} 8$ & 79 & 55 & 104 & 109 & 24 & 179 & 180 & 112 \\
up & 62 & 40 & 48 & 86 & 20 & 86 & 100 & 47 \\
down & 17 & 15 & 56 & 23 & 4 & 93 & 80 & 65 \\
T485 $\times$ H8 & 48 & 61 & 39 & 77 & 15 & 67 & 193 & 51 \\
up & 21 & 41 & 32 & 58 & 7 & 32 & 63 & 23 \\
down & 27 & 20 & 7 & 19 & 8 & 35 & 130 & 28 \\
$\%$ & 4.65 & 4.39 & 5.70 & 6.78 & 3.04 & 5.58 & 6.38 & 4.72
\end{tabular}

0-L, Flag Leaf; 0-S, Leaf sheath; 0-P, Spikelet; 0-Z, Main panicle axis before flowering; 5-L, Flag leaf; 5-S, Leaf sheath; 5-P, Spikelet; $5-Z$, Main panicle axis 5 days after flowering

$\%$ : indicate the percent ratio of NDEGs to DEGFu-sp genes had known functions in rice (Additional file 4: Table S12b). A total of 59 specific mutant genes were detected in $\mathrm{H} 8$, including large panicle gene $L P\left(L O C_{-}\right.$ Os02g15950), LPA1 (LOC_Os03g13400), dwarf 61 (LOC_ Os01g52050), dwarf 10 (LOC_Os01g54270), cellulose synthase catalytic subunit A4 (LOC_OsO1g54620, OsCesA4), and LAX PANICLE (LOC_OsO1g61480) (Additional file 4: Table S12c). Moreover, H8 had missense variants in $H d 1$ compared to $\mathrm{H} 1$, while $\mathrm{H} 1$ exhibited a missense variant in NAL1 compared to Nipponbare reference genome. T485 had a missense variant in OsGA20ox1 compared to H8. Twelve specific mutated genes related to rice panicle architecture were also identified in $\mathrm{H} 8$, including OsClpC2, OsClpC3, LPL3, OsGLP8-12, SP1 (OsNPF4.1), OsERF71, OsHSP1, OsHSP17.7, spl5 (SF3b3; OsSL5), SPL35 and SPL3 (OsEDR1; OsACDR1; OsMAPKKK1).

In order to check the DNA variations in LP gene, we analyzed the re-sequencing data of 132 different rice lines, including 67 neo-tetraploid (including sister lines), 36 autotetraploid and 29 diploid rice lines. The results displayed that the DNA variations in LP gene of $\mathrm{H} 8$ were different from most of the other neo-tetraploid, autotetraploid and diploid rice lines (Additional file 1: Figure S7). The DNA sequences of LP gene in three parents, H8, H1 and T485, were validated by using Sanger sequencing, and the results were consistent with the data of re-sequencing.

Since many DNA sequences variations were detected among three parents, H1, T485 and H8, we focused on the gene variations in DEGFu-sp. A total of 33 genes showed DNA sequence variations (Additional file 4: Table S13a), including 3TE, 13 resistance or tolerance genes, 10 and 19 genes were associated with physiological and morphological traits, respectively (Additional file 4: Table S13b).

\section{Functional analysis of DEGs associated with panicle length and grain number in neo-tetraploid rice with large panicle}

In order to check the DEGs and important genes associated with panicle length and number of grains per panicle in neo-tetraploid rice with large panicle, RNA-seq was employed to analyze global gene expressions in very young panicles of $\mathrm{H} 1 \times \mathrm{H} 8$ vs $\mathrm{H} 1$ (short panicle), $\mathrm{H} 8$ vs H1, T485 $\times$ H8 vs T485, and H8 vs T485. A total of eight up-regulated genes associated with panicle were detected in young panicles of the two hybrids compared with their parents, including OsMADS3, OsMADS6 (mfo1), MADS58, Gn1a, OsClpC2, OsLG1, MULTI-FLORET SPIKELET1 and LAX PANICLE. The expression patterns of eight genes associated with length and grain number of panicle and heterosis, including $L P$, Ghd8, NAL1, GW6a, IPA1, GA200x1, Hd1 and GW8, were detected 
using qRT-PCR during different stages of panicle development. The results showed that the eight genes were found to be up-regulated in $\mathrm{H} 1 \times \mathrm{H} 8$ vs $\mathrm{H} 8$ in very young stage of panicle development, and $L P$ displayed up-regulation in $\mathrm{H} 1 \times \mathrm{H} 8$ compared to both parents in young panicles (Fig. 4). Predicted protein-protein interaction analysis of above mentioned eight genes and 133 cloned genes displayed interaction with each other (Fig. 5; Additional file 4: Table S14). Moreover, the segregation ratio of panicle length of $\mathrm{H} 1 \times \mathrm{H} 8$ was investigated in $F_{2}$ generation, and the mean length of panicle was $24.61 \mathrm{~cm}$, which was very close to the average length of two parents $(24.69 \mathrm{~cm})$. There were 12 plants with longer panicles than that of $\mathrm{H} 8$, and 19 with shorter panicles than that of $\mathrm{H} 1$, with the shortest $14 \mathrm{~cm}$. The average seed setting was $71.51 \%$ in the $F_{2}$ generation, suggesting that most of the plants maintained high seed set in next generation.

\section{Discussions}

The neo-tetraploid rice with long panicle is a widecompatibility germplasm and many important genes were associated with high hybrid vigor

Hybrid sterility not only exists in intersubspecific diploid rice hybrids but also in autotetraploid rice hybrids, which caused by the allelic interaction of $F_{1}$ sterility loci, including $S a, S b$ and $S c$, and their neutral alleles have the potential to overcome the hybrid sterility $[14,15,17,45,46]$. In the present study, the closely linked molecular markers associated with $S a, S b$ and $S c$ loci were used to detect the genotypes of Huaduo 8 (H8) at three loci, which was similar to E249, harboring $S a-n$ and $S b-n$ at $S a$ and $S b$ loci, and similar to E25 and T45, which contained Sc-n at Sc locus. Meanwhile, 14 hybrids, including 10 hybrids generated by crossing H8 with indica autotetraploid rice and 4 with japonica tetraploid rice, displayed high seed setting and hybrid vigor like Huaduo 1 and Huaduo 3 [16, 17]. These results suggested that $\mathrm{H} 8$ contain neutral genes for pollen sterility loci. Moreover, the genotype at $S_{5}$ locus, which causes embryo sac sterility in intersubspecific hybrids, was detected using $S_{5}$ functional molecular marker and $\mathrm{H} 8$ harbored $S_{5}{ }^{n}$ gene as well (neutral allele at $S_{5}$ locus). Interestingly, almost all plants displayed high seed setting in $F_{2}$ and next generations. Therefore, we inferred that $\mathrm{H} 8$ is a new wide-compatibility neo-tetraploid rice, which will be a valuable germplasm for polyploid rice breeding.

The neo-tetraploid rice with long panicle possess high hybrid vigor and many important genes associate with heterosis in diploid rice were also detected in the neotetraploid rice hybrids, including OsGA20ox2, qSD1-2, $H d 3 a, D E P 1$, and qGW8 [36]. The transcription factors (TFs), as important regulatory genes, affect the phenotypes of rice hybrids [23]. Interestingly, most of TFs with differential expression patterns in the two hybrids of neo-tetraploid rice were different from those in diploid rice hybrid [23]. Moreover, we also detected many DEGFu-sp associated with NBS-LRR disease resistance protein, and most of them were also different from those in diploid rice hybrid [23]. Non-additive genes have pronounced effects on the plant phenotypes, and had been detected in rice or autotetraploid rice hybrids $[16,17$, 23]. Here, a total of 1393 non-additive DEGs were also identified. Kinase and synthase, such as protein kinase and starch synthase, played important role in heterosis performance [23, 43]. We found many genes involved in kinase and synthase, and the KEGG analysis results revealed an important pathway, i.e. STARCH AND SUCROSE METABOLISM, which was consistent with the results of genes detection. These results showed that many important genes were involved in the high hybrid vigor of neo-tetraploid rice and it's a very useful germplasm to decipher the underlying mechanism of hybrid vigor in polyploid rice.

\section{Many yield-related QTLs contributed to high heterosis in neo-tetraploid rice}

The molecular mechanisms underlying heterosis is very complicated in rice, and many functional genes or QTLs

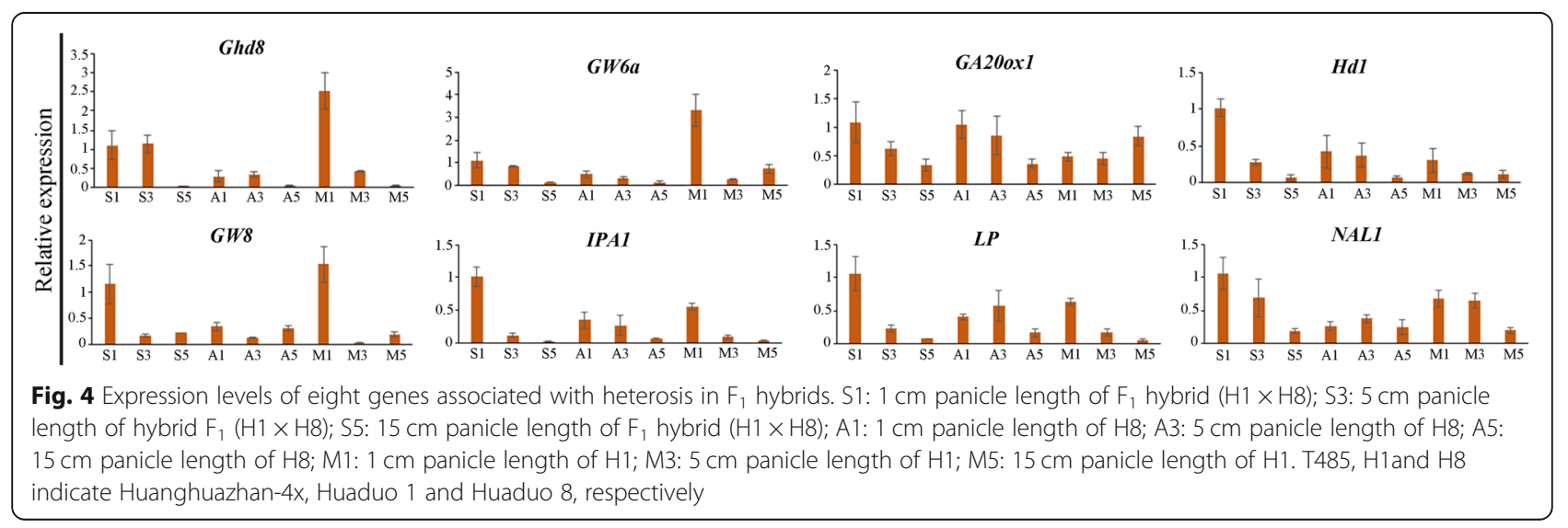




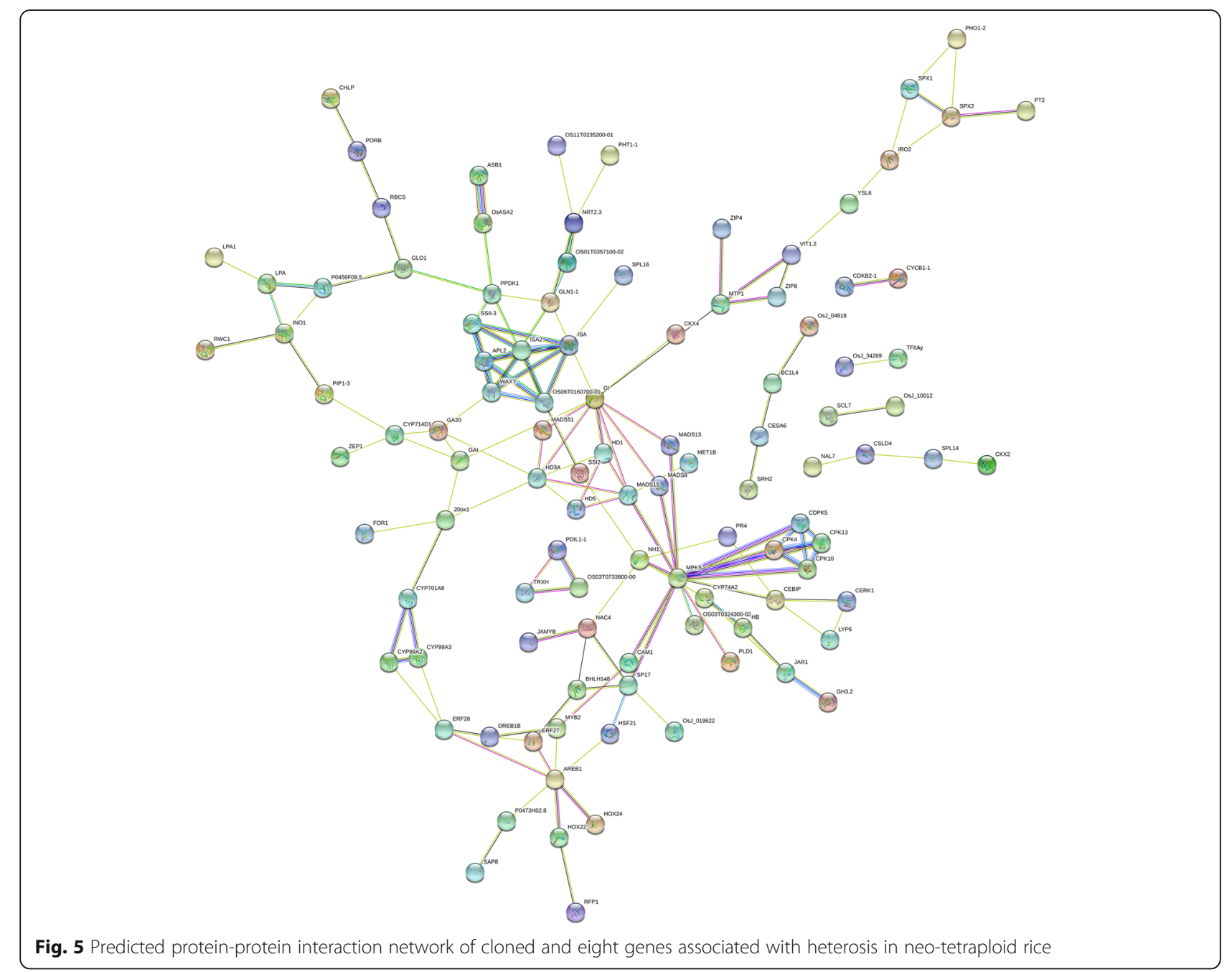

had been detected in diploid rice hybrids. The gene expression profiles of super hybrid rice, LYP9, were investigated by gene-chip and found that the genes uniquely belonging to $F_{1}$ hybrid compared to parents, and were enriched in the categories of energy metabolism and transport. Moreover, 2673 differentially expressed genes between hybrids and parents (DGHP) were mapped onto 3128 QTLs, and 53 were uniquely belonging to differentially expressed genes between hybrids and parents (DGHPU), which were classified into 9 categories and 209 traits in the rice genome [23]. Many QTLs, including $H d 3 a, q G L 3$, OsmiR156h, and LAX2, and nonadditive genes related to the yield-related traits in twoline hybrid rice, were identified [47]. A total of 22 yieldrelated QTLs, including 15 grain number QTLs, 61000grain weight QTLs and 1 yield per plant QTL that contributed largely to the grain number heterosis, were detected in a super-hybrid rice WFYT025 [48]. More than 90\% of the DEGFu-sp genes detected during different development stages (anthers and flag leaves at meiosis stage, flag leaves, leaf sheath, anther and ovary at preflowering stage, and flag leaves, leaf sheath and grains at 3 days after flowering) were mapped onto 1019 yieldrelated QTLs and 26 traits present in the rice Gramene database [17].

In the present study, we detected 2925 QTLs intervals, with a frequency of 1 100 genes per interval, and 975 were the same in the two hybrids, including 109 rice yield-related QTLs. Among the QTLs, 50 QTLs were the same as detected in our previous studies in the two neo-tetraploid rice hybrids (Huajingxian 74-4x $\times$ Huaduo 3 and T449 $\times$ Huaduo 1) [16, 17], such as two for 1000grain weight (AQAI071 and CQB16), and three for seed set (AQGH011, AQGH028 and CQB14). Interestingly, some important genes-related QTLs, such as JMJ706, OsClpB-m, Alpha amylase and OsLpa1, and 26 specific QTLs were also found in the two neo-tetraploid rice hybrids. We inferred that the molecular mechanism involved in heterosis is complicated in the neo-tetraploid rice hybrid. There are at least five genetic factors that 
affect the phenotypes and produce high heterosis in the neo-tetraploid rice hybrids, including major functional genes, QTLs, TFs, NBS-LRR and epigenetic-related genes.

\section{The up-regulation and mutant genes association with panicle length may involve in the long panicle of neo- tetraploid rice, $\mathrm{H} 8$}

There is a large genetic variance for panicle length of indica and japonica in rice. In general, japonica has short panicle and dense spikelet compared to indica, which is characterized by longer panicles and sparse spikelet $[49,50]$. Panicle length was controlled by both major and minor QTLs in rice [51], and more than 253 QTLs and genes for panicle length distributed on 12 chromosomes have been reported [52-54]. A major rice grain yield QTL, DEP1, was identified, which increased number of grains per panicle by enhancing meristematic activity to reduce length of the inflorescence internode [36]. The larger panicle mutant gene, $L P$, could significantly increase panicle size, and encode F-box protein that could interact with rice SKP1-like protein [37].

In the present study, we detected 8 genes, including OsMADS3, osmads6 (mfo1), mads58, Gn1a, "OsClpC2", OsLG1, MULTI-FLORET SPIKELET1 and LAX PAN$I C L E$, involved in the panicle architecture, which displayed up-regulation expression in $F_{1}$ compared to parents. Among these genes, Gn1a controlled the filled grains per panicle [38]; OsLG1 regulated a closed panicle trait in rice [55]. Actually, $\mathrm{H} 8$ is a neo-tetraploid rice with large and closed panicle trait, and the up-regulated expression patterns of these two genes, Gnla and OsLG1, play important role in its panicle development. Moreover, we also detected DNA variations in some large panicle related genes, such as large panicle gene, $L P$.

\section{Conclusion}

Here, we developed a neo-tetraploid rice line, Huoduo8, with long panicles, which could overcome intersubspefic hybrid sterility of autopolyploid rice. Huaduo 8 produced high heterosis when crossed with different autotetraploid and neo-tetraploid rice lines. We detected a total of $368 \mathrm{DEGFu}$-sp genes associated with kinase and synthase and 975 DEGFu-sp-related QTLs in the two hybrids generated by Huaduo 8. A total of eight genes, including a mutant allele of $L P$, related to rice panicle architecture, exhibited up-regulated expression patterns in very young panicles. Our research provided a very useful germplasm for breeding of high yielding polyploid rice, and provided insight into molecular mechanisms associated with heterosis in neo-tetraploid rice. Overall, molecular regulatory mechanism of heterosis is very complicated in neo-tetraploid rice, and future studies should be focused on the functional characterization of the genes associated with heterosis.

\section{Methods \\ Evaluation of heterosis in a neo-tetraploid rice with large panicle}

The materials used in this study were comprised of nine autotetraploid and five neo-tetraploid rice lines, which were crossed with a neo-tetraploid rice line with long panicle, Huaduo 8 (H8), to develop 14 hybrids (Additional file 2: Table S1). All the parents and their $F_{1} \mathrm{~s}$ were planted under the natural conditions at the experimental farm of South China Agricultural University (SCAU), Guangzhou $\left(23^{\circ} 16 \mathrm{~N}, 113^{\circ} 8 \mathrm{E}\right)$ in two growing seasons i.e. late season (20th July to 30th November, 2017) and early season (25th February to 15th July, 2018). All the lines, except L202-4x, Jackson-4x and Luxiang 97-4x were kindly provided by Prof. Yuanqing $\mathrm{Li}$, used in this study are produced by our research group and is being used from last several years $[5-7,10$, $16,18]$. The voucher specimen of polyploid rice lines has been deposited to our lab but not to any publicly available herbarium. We didn't use wild plants in this study and according to national and local legislation, no specific permission was required to collect these plants.

A total of 15 plants from all $F_{1}$ hybrids and their parents were harvested from the middle part of the field at maturity. Agronomic traits, including panicle length $(\mathrm{PL}, \mathrm{cm})$, plant height $(\mathrm{PH}, \mathrm{cm})$, effective number of panicles per plant (NP), filled grains per plant (FG/P), 1000-grain weight (GWT, g), grain yield per plant (GY, g), and seed setting (SS\%) were selected and measured according to our previous study [16]. In order to detect the genotypes at $F_{1}$ pollen sterility loci, $S a, S b$ and $S c$, and at $S 5$ embryo sac sterility locus, molecular markers were used. Here, closely linked molecular markers were employed to detect genotypes at known loci, including one SNP marker (G02-148) for $\mathrm{Sa}$ locus, two markers (A07-55 and A07-130) for $\mathrm{Sb}$ locus, one marker (P24-85.7) for Sc locus, and one marker (S5t1) to detect neutral gene $\left(S_{5}{ }^{n}\right)$ at S5 locus (Additional file 2: Table S15) $[45,46]$.

We analyzed the data and estimated the heterosis of hybrids in three replications during both seasons. The single factor variance analysis of each trait was done by SPSS 16.0 using 0.05 and 0.01 significance levels. Midparent heterosis (MPH) and high-parent heterosis $(\mathrm{HPH})$ were determined by the following formula: $\mathrm{MPH}=\left(\mathrm{F}_{1}-\mathrm{MP}\right) / \mathrm{MP} \times 100 \%$, and $\mathrm{HPH}=\left(\mathrm{F}_{1}-\mathrm{HP}\right) / \mathrm{HP} \times$ $100 \%$, where MP is the average performance of two parents, $F_{1}$ is the performance of first generation (hybrid), and $\mathrm{HP}$ is the performance of the best parent. 
Genome-wide DNA variations in a neo-tetraploid rice with large panicle and other parents

Young leaves of H8, Huanghuazhan-4x (T485) and Huaduo1 (H1) were collected and stored at $-80{ }^{\circ} \mathrm{C}$ for DNA isolation. Genomic DNA was extracted from each young leaf tissue by using a modified CTAB method [56]. The task of whole-genome re-sequencing was done by Biomarker Technologies (Beijing, China) on Illumina HiSeq platform. The method was performed in accordance with the standard Illumina protocol as described previously [57].

The quality of sequencing raw reads was evaluated by FastQC software, and the filtered high quality reads were aligned to the Nipponbare reference genome (MSU7) using BWA software. Genomic variations (InDels and SNPs) were detected using GATK software (https:// www.broadinstitute.org/gatk/guide/best-practices.php).

The InDels and SNPs were annotated based on the GFF3 file of the reference genome using SnpEff software. According to the location of the polymorphisms, the genic SNPs and InDels were classified as CDS (coding sequences), UTR (untranslated regions) and introns. The SNPs in coding sequencing were classified as synonymous and non-synonymous.

\section{RNA extraction, cDNA library construction, and RNA-Seq}

Eight tissues, including flag leaf, leaf sheath, main panicle axis (including rachis and all branches but not spikelet), and spikelet (not including anther) at flowering stage before fertilization and 5 days after flowering were collected from two $\mathrm{F}_{1}$ hybrids (T485 $\times \mathrm{H} 8$ and $\mathrm{H} 1 \times \mathrm{H} 8$ ) and their parents (Additional file 1: Figure S8; Additional file 2: Table S1;). Moreover, the young panicles with a length of less $0.5 \mathrm{~cm}$ were also collected from the two hybrids and their parents. All the samples were collected in three biological replications and kept at $-80^{\circ} \mathrm{C}$ for RNA extraction.

The total RNA from each sample was extracted based on the manual instruction of the TRlzol Reagent (Life technologies, California, USA), and libraries were prepared as described previously [16]. The quality and quantity of all the samples were evaluated by a Nanodrop 1000 spectrophotometer and 1\% agarose gel. An Agilent 2100 Bioanalyzer (Agilent Technologies, Inc., USA) was used to estimate the number and RNA integrity concentration. NEBNext Poly (A) mRNA magnetic extraction module was employed to extract the mRNA. The first- and second-strand cDNA were produced by breaking the purified and enriched mRNA into about $200 \mathrm{nt}$ short RNA inserts. The end-repair/dA-tail and adaptor ligation was executed of double-stranded cDNA. AgencourtAMPure XP beads (Beckman Coulter, Inc.) were used to extract the appropriate fragments, and amplified by PCR. Then, an Illumina $\mathrm{HiSeq}^{\mathrm{Tm}} 2500$ sequencing platform was employed to sequence the cDNA libraries [16, 18].

The low quality reads were eliminated by perl script as described previously [16]. The filtered clean reads were mapped onto Nipponbare reference genome (IRGSP-1.0 pseudomolecule/MSU7) using Tophat2software and Bowtie2 [58]. The aligned data were further checked to eliminate potential duplicate reads. The Cufflinks software was used to assess gene expression patterns by Fragments Per Kilobase of transcript per Million fragments mapped (FPKM) [59].

Differentially expressed genes (DEGs) between $\mathrm{F}_{1} \mathrm{~s}$ and their parents were evaluated by DESeq. Then, gene abundance differences between $\mathrm{F}_{1} \mathrm{~s}$ and their parents were estimated based on the ratio of the FPKM values. To calculate the significant differences, the false discovery rate (FDR) control method was applied to detect the the $P$-value in various investigations. In the present study, the genes with FDR significance score $<0.01$ and an absolute fold change value $\geq 2$ was used for further analysis $[16,18]$.

Gene Ontology (GO) analysis was conducted to annotate the DEGs using the AgriGO tool (http://bioinfo.cau. edu.cn/agriGO/), and Pathway analysis was done by Plant GeneSet Enrichment Analysis Toolkit (http:// structuralbiology.cau.edu.cn/ PlantGSEA/). Cluster analysis was performed using Cluster 3.0 software. Predicted protein-protein interaction analysis was performed using STRING software (http://www.string-db.org/). Venny software was employed to detect the overlapped differentially expressed genes in different samples and tissues (http://bioinfogp.cnb.csic.es/tools/venny/) [14].

\section{Mapping of DEGFu-sp to rice QTLs}

Rice QTL data with physical positions on the MSU Rice Genome Annotation Project Release 6.1 were acquired from Gramene (ftp://ftp.gramene.org/pub/gramene/archives/qtl/) [60]. The DEGFu-sp were mapped onto the seven yield-related QTLs, including total biomass yield (TBIOMYLD), biomass yield (BIOMYLD), filled grain number (FGRNB), grain number (GRNB), panicle number (PNNB), seed set percent (SDSPCENT) and 1000grain weight (TGRWT), using gene coordinates from the MSU Rice Genome Annotation Project (Additional file 4: Table S16) (http://qtaro.abr.affrc.go.jp/) [17, 23].

\section{qRT-PCR}

A total of 30 DEGs were randomly selected from the transcriptome data of eight tissues to validate RNA-seq data by qRT-PCR with eight primers. Moreover, we designed another eight primers to observe the expression patterns of eight genes during development of panicle, including $1 \mathrm{~cm}, 5 \mathrm{~cm}$ and $15 \mathrm{~cm}$ long panicles (Additional file 4: Table S15). The Transcriptor First Strand 
cDNA Synthesis Kit (Roche) was used to obtain firststrand cDNA from approximately $1 \mu \mathrm{g}$ of extracted RNA as described previously [16]. The components of each reaction was $10 \mu \mathrm{M}$ of forward and reverse primers, $10 \mu \mathrm{L}$ of universal SYBR Green supermix (Bio-RAD) and $2 \mu \mathrm{L}$ of cDNA and the final volume of each qRT-PCR reaction was $20 \mu \mathrm{L}$. The PCR reaction program was denaturation for $30 \mathrm{~s}$ at $95^{\circ} \mathrm{C}$ followed by 40 cycles of amplification (i.e. $95^{\circ} \mathrm{C}$ for $5 \mathrm{~s}$ and $60^{\circ} \mathrm{C}$ for $30 \mathrm{~s}$ ). We utilized rice Actin gene as an internal control, and all the reactions were executed in triplicate. The $2^{-\Delta \Delta C T}$ method was applied to estimate the relative expression patterns [61].

\section{Supplementary information}

Supplementary information accompanies this paper at https://doi.org/10. 1186/s12870-020-2291-z.

Additional file 1: Figure S1a. Breeding procedure of Huaduo 8. Figure S1b Panicles of Huaduo $1(\mathrm{H} 1)$, Huaduo $8(\mathrm{H} 8)$ and their $F_{1}$ hybrid. Figure S1c Plant appearance of parents and $F_{1}$ hybrid generated by crossing with Huaduo 8 ( $\mathrm{H} 8)$. Figure $\mathbf{S 2}$ Original images of genotypes of parental lines at pollen sterility loci (Sa, Sb and Sc) and S5 locus detected by molecular markers. Figure $\mathbf{S} 3$ qRT-PCR validation for the quality of transcriptomic data. Figure S4 Hierarchical clustering analysis of all expressed genes based on transcriptome data. Figure S5 Prominent functional categories of genes in the eight tissues detected by Gene ontology enrichment analysis before and 5 days after flowering in two hybrids. Figure S6 Distribution of the common seven yield-related QTLs in the two $\mathrm{F}_{1}$ hybrids, $\mathrm{T} 449 \times \mathrm{H} 1$ [17] and T452 $\times \mathrm{H} 3$ [16], compared to the DEGFu-sp-related QTLs detected in the present study. Figure $\mathbf{S 7}$ Cluster analysis of the DNA variations in LP gene of Huaduo 8. Figure $\mathbf{S 8}$ Samples used for RNA-seq analysis.

Additional file 2: Table S1. Origin and genotypes of autotetraploid and neo-tetraploid rice lines at pollen sterility loci, Sa, Sb, and Sc, and embryo sac fertility locus (S5), and their agronomic traits. Table S2. Means of mid-parent and high-parent heterosis in $F_{1}$ during two seasons of 2017 and 2018. Table S3. Means of agronomic traits of $F_{1}$ in two seasons of 2017 and 2018. Table S4a. Codes and names of the parents, hybrids, tissues and development stages. Table S4b. Summary of clean reads of transcriptome data from the two $\mathrm{F}_{1}$ hybrids $(\mathrm{H} 1 \times \mathrm{H} 8$ and $\mathrm{T} 485 \times \mathrm{H} 8)$ and their parents. Table S5 Differentially expressed genes associated with the $F_{1}$ hybrids compared to parents in flag leaf, leaf sheath, spikelet and main panicle axis. Table S6 Differentially expressed genes associated with parents in flag leaf, leaf sheath, spikelet and main panicle axis. Table S7 Gene IDs of differentially expressed genes that uniquely associated with $F_{1}$ compared to parents and specific (DEGFu-sp) to flag leaf, leaf sheath, spikelet and main panicle axis. Table S8a Prominent functional categorization of genes in the eight tissues before and 5 days after flowering in the $\mathrm{F}_{1}$ hybrid $(\mathrm{H} 1 \times \mathrm{H} 8)$ by Gene ontology $(\mathrm{GO})$ enrichment analysis. Table S8b Prominent functional categorization of genes in the eight tissues before and 5 days after flowering in the $F_{1}$ hybrid (T485 $\times$ $\mathrm{H8}$ ) by Gene ontology ( $\mathrm{GO}$ ) enrichment analysis. Table S8c List of the functional categorization of genes in the hybrids by Gene ontology (GO) enrichment analysis. Table S8d Common prominent functional categorization of genes by Gene ontology (GO) enrichment analysis. Table S8e KEGG Pathway analysis of DEGFu-sp to the two hybrids.

Additional file 3: Table S9a The common genes associated with kinase in DEGFu-sp to both hybrids. Table $\mathbf{5 9 b}$ The common genes associated with synthase in DEGFu-sp to both hybrids. Table S9c The common genes associated with NBS-LRR disease resistance protein or LRR receptor-like protein kinase in DEGFu-sp to both hybrids. Table S9d The common genes associated with transcription factors in DEGFu-sp to both hybrids. Table S9e The known genes associated with important agronomic traits detected from the DEGFu-sp to both hybrids. Table S10a
Names of all DEGFu-sp-related QTLS in the $\mathrm{F}_{1}$ hybrids $(\mathrm{H} 1 \times \mathrm{H} 8$ and T485 $\times$ H8). Table S10b Names of the DEGFu-sp yield-related QTLS in the $\mathrm{F}_{1}$ hybrids $(\mathrm{H} 1 \times \mathrm{H} 8$ and $\mathrm{T} 485 \times \mathrm{H} 8)$. Table S10c Names of the DEGFu-sp-related common QTLS in the $\mathrm{F}_{1}$ hybrids $(\mathrm{H} 1 \times \mathrm{H} 8$ and $\mathrm{T} 485 \times$ H8). Table S10d Names of the DEGFu-sp-related common QTLS among the four $F_{1}$ hybrids $(H 1 \times H 8, T 485 \times H 8, T 449 \times H 1$ and $\mathrm{T} 452 \times H 3)$. Table S10e Names and differential expressions of important DEGFu-sp genes in $F_{1}$ hybrid $(\mathrm{H} 1 \times H 8)$. Table S10f Names and differential expression of important DEGFu-sp genes in $\mathrm{F}_{1}$ hybrid (T485 $\times \mathrm{H} 8$ ).

Additional file 4: Table S11a, b Gene IDs of DEGFu-sp-non-additive in the $F_{1}$ hybrids. Table $\mathbf{S 1 1 c , d}$ Overlapped genes detected from DEGFusp-non-additive and cloned genes in $F_{1}$ hybrids. Table S12a Overlapped genes detected from DEGFu-sp-cloned and mutant genes in $\mathrm{H} 8 \mathrm{com}$ pared to H1. Table S12b Overlapped genes detected from DEGFu-spcloned and mutant genes in H8 compared to T485. Table S12c Overlapped genes detected from DEGFu-sp-cloned and all common mutant genes in $\mathrm{H} 8$ compared to $\mathrm{H} 1$ and T485. Table S13a Overlapped genes detected from DEGFu-sp and mutant genes in $\mathrm{H} 8$ compared to $\mathrm{H} 1$ and T485. Table S13b Overlapped genes detected from DEGFu-sp, mutant and cloned genes in $\mathrm{H} 8$ compared to $\mathrm{H} 1$ and T485. Table S14 Predicted protein-protein interaction analysis of the cloned genes in DEGFu-sp. Table S15 List of primers used for PCR and qRT-PCR. Table S16 Name of 7 yield-related QTLs.

\section{Abbreviations}

DEGFu-sp: Specific and differentially expressed genes uniquely belonging to $F_{1}$ hybrid compared to parents; DEGs: Differentially expressed genes; HPH: High parent heterosis; MPH: Mid parent heterosis; TFs: Transcription factors

\section{Acknowledgements}

The authors thank Prof. Yuanqing Li for donating L202-4x, Jackson-4x and Luxiang 97-4x. We also thank Ms. Shuhong Yu and other lab members for assistance.

\section{Authors' contributions}

XDL conceived and designed the experiments. MAAG, MQS and XDL wrote the paper. MAAG, CL, JHL, RXC, MQS, HY, XDL and JWW performed the experiment and analyzed the data. XDL developed the neo-tetraploid and autotetraploid rice. All authors read and approved the final version of manuscript.

\section{Funding}

This work was supported by the Guangzhou Science and Technology Key Program to XD Liu (201707020015), the National Natural Science Foundation of China (NSFC) to XD (31571625), the Key Realm R \& D Program of Guangdong Province (2018B020202012) and the National Natural Science Foundation of China (NSFC) to MQS (31850410472). The funders had no role in the design of the study and collection, analysis, and interpretation of data and in writing the manuscript.

\section{Availability of data and materials}

All datasets supporting the conclusions of manuscript are provided in the main manuscript (Figures and Tables), additional files, and also deposited in publicly available repository (NCBI). The RNA-seq and Re-sequencing data are available from the NCBI under the accession number PRJNA576043 (https:// www.ncbi.n/m.nih.gov/bioproject/PRJNA576043).

\section{Ethics approval and consent to participate}

Plant samples used in the study were not collected from national park or natural reserve. According to national and local legislation, no specific permission was required for collecting these plants. We confirm that this complies with national guidelines and no formal ethics approval was required in this particular case.

\section{Consent for publication}

Not applicable.

\section{Competing interests}

The authors declare that they have no competing interests. 


\section{Author details}

State Key Laboratory for Conservation and Utilization of Subtropical Agro-Bioresources, South China Agricultural University, Guangzhou 510642, China. ${ }^{2}$ Guangdong Provincial Key Laboratory of Plant Molecular Breeding, South China Agricultural University, Guangzhou 510642, China. ${ }^{3}$ College of Agriculture, South China Agricultural University, Guangzhou 510642, China. ${ }^{4}$ Guangdong Laboratory for Lingnan Modern Agriculture, Guangzhou 510642, China.

Received: 5 August 2019 Accepted: 14 February 2020

Published online: 21 February 2020

\section{References}

1. Kohnaki ME, Kiani G, Nematzadeh G. Relationship between morphological traits in rice restorer lines at $F_{3}$ generation using multivariate analysis. Int J Adv Biol Biomed Res. 2017:5(4):160-3.

2. Cheng SH, Zhuang JY, Fan YY, Du JH, Cao LY. Progress in research and development on hybrid rice: a super-domesticate in China. Ann Bot. 2007; 100:959-66.

3. Godfray HCJ, Beddington JR, Crute IR, Haddad L, Lawrence D, Muir JF, Pretty J, Robinson S, Thomas SM, Toulmin C. Food security: the challenge of feeding 9 billion people. Science. 2010;327:812-8.

4. Sasson A. Food security for Africa: an urgent global challenge. Agric Food Secur. 2012;1:1-16.

5. Shahid MQ, Liu G, Li J, Naeem M, Liu X. Heterosis and gene action study of agronomic traits in diploid and autotetraploid rice. Acta Agric Scand Sect B Soil Plant Sci. 2011;61:23-32.

6. Shahid MQ, Xu H, Lin S, Chen Z, Naeem M, Li Y, Liu X. Genetic analysis and hybrid vigor study of grain yield and other quantitative traits in autotetraploid rice. Pak J Bot. 2012;44(1):237-46.

7. Wu J, Hu C, Shahid MQ, Guo H, Zeng Y, Liu X, Lu Y. Analysis on genetic diversification and heterosis in autotetraploid rice. Springer Plus. 2013;2:1-12.

8. He J, Shahid MQ, Chen Z, Chen X, Liu X, Lu Y. Abnormal PMC microtubule distribution pattern and chromosome behavior resulted in low pollen fertility of an intersubspecific autotetraploid rice hybrid. Plant Syst Evol. 2011;291:257-65.

9. Ghouri F, Zhu J, Hu H, Wu J, Baloch FS, Liu X, Shahid MQ. Deciphering global DNA variations and embryo sac fertility in autotetraploid rice line. Turk J Agric For. 2019;43:554-68.

10. Shahid MQ, Sun J, Wei C, Zhang P, Liu X. Studies on the abnormality of embryo sac and pollen fertility in autotetraploid rice during different growing seasons. Pak J Bot. 2010;42(1):7-19.

11. Shahid MQ, Li Y, Saleem MF, Naeem M, Wei C, Liu X. Yield and yield components in autotetraploid and diploid rice genotypes (indica and japonica) sown in early and late seasons. Aust J Crop Sci. 2013;7(5):632-41.

12. Wu J, Shahid MQ, Guo H, Yin W, Chen Z, Wang L, Liu X, Lu Y. Comparative cytological and transcriptomic analysis of pollen development in autotetraploid and diploid rice. Plant Reprod. 2014;27:181-96.

13. Chen L, Shahid MQ, Wu J, Chen Z, Wang L, Liu X. Cytological and transcriptome analyses reveal abrupt gene expression for meiosis and saccharide metabolisms that associated with pollen abortion in autotetraploid rice. Mol Gen Genomics. 2018;293(6):1407-20.

14. Wu J, Shahid MQ, Chen L, Chen Z, Wang L, Liu X, Lu Y. Polyploidy enhances $F_{1}$ pollen sterility loci interactions that increase meiosis abnormalities and pollen sterility in autotetraploid rice. Plant Physiol. 2015;169(4):2700-17.

15. Wu J, Chen L, Shahid MQ, Chen M, Dong Q, Li J, Xu X, Liu X. Pervasive interactions of $\mathrm{Sa}$ and $\mathrm{Sb}$ loci cause high pollen sterility and abrupt changes in gene expression during meiosis that could be overcome by double neutral genes in autotetraploid rice. Rice. 2017:10:49.

16. Guo H, Mendrikahy JN, Xie L, Deng J, Lu Z, Wu J, Li X, Shahid MQ, Liu X. Transcriptome analysis of neo-tetraploid rice reveals specific differential gene expressions associated with fertility and heterosis. Sci Rep. 2017;7: 40139.

17. Chen L, Yuan Y, Wu J, Chen Z, Wang L, Shahid MQ, Liu X. Carbohydrate metabolism and fertility related genes high expression levels promote heterosis in autotetraploid rice harboring double neutral genes. Rice. 2019: $12: 34$

18. Bei X, Shahid MQ, Wu J, Chen Z, Wang L, Liu X. Re-sequencing and transcriptome analysis reveal rich DNA variations and differential expressions of fertility-related genes in neotetraploid rice. PLoS One. 2019; 14(4):e0214953.1-23.

19. Yu Z, Haage $K$, Streit VE, Gierl A, Ruiz RA. A large number of tetraploid Arabidopsis thaliana lines, generated by a rapid strategy, reveal high stability of neo-tetraploids during consecutive generations. Theor Appl Genet. 2009; 118:1107-19.

20. Hu J, Chen G, Zhang H, Qian Q, Ding Y. Comparative transcript profiling of alloplasmic male-sterile lines revealed altered gene expression related to pollen development in rice (Oryza sativa L.). BMC Plant Biol. 2016;16:175.

21. Fu C, Wang F, Liu W, Liu D, Li J, Zhu M, Liao Y, Liu Z, Huang H, Zeng X, et al. Transcriptomic analysis reveals new insights into high-temperaturedependent glume-unclosing in an elite rice male sterile line. Front Plant Sci. 2017:8:112.

22. Li X, Yu H, Jiao Y, Shahid MQ, Wu J, Liu X. Genome-wide analysis of DNA polymorphisms, the methylome and transcriptome revealed that multiple factors are associated with low pollen fertility in autotetraploid rice. PLoS One. 2018;13:8

23. Wei G, Tao Y, Liu G, Chen C, Luo R, Xia H, Gan Q, Zeng H, Lu Z, Han Y, et al. A transcriptomic analysis of superhybrid rice $\angle Y P 9$ and its parents. Proc Natl Acad Sci U S A. 2009;106(19):7695-701.

24. Shankar R, Bhattacharjee A, Jain M. Transcriptome analysis in different rice cultivars provides novel insights into desiccation and salinity stress responses. Sci Rep. 2016;6:23719.

25. Tian M, Nie Q, Li Z, Zhang J, Liu Y, Long Y, Wang Z, Wang G, Liu R. Transcriptomic analysis reveals overdominance playing a critical role in nicotine heterosis in Nicotiana tabacum L. BMC Plant Biol. 2018;18:48.

26. Nirmal RC, Furtado A, Wrigley C, Henry RJ. Influence of gene expression on hardness in wheat. PLoS One. 2016;11(10):e0164746.

27. Liu Y, Gao S, Tang Y, Gong J, Zhang X, Wang Y, Zhang L, Sun R, Zhang Q, Chen $Z$, et al. Transcriptome analysis of wheat seedling and spike tissues in the hybrid Jingmai 8 uncovered genes involved in heterosis. Planta. 2018; 247(6):1307-132.

28. Shen Y, Sun S, Hua S, Shen E, Ye C, Cai D, Timko MP, Zhu Q, Fan L. Analysis of transcriptional and epigenetic changes in hybrid vigor of allopolyploid Brassica napus uncovers key roles for small RNAs. Plant J. 2017;91(5):874-93.

29. Ma J, Zhang D, Cao Y, Wang L, Li J, Lubberstedt T, Wang T, Li Y, Li H. Heterosis related genes under different planting densities in maize (Zea mays L.). J Exp Bot. 2018:69(21):5077-87.

30. Huang Y, Zhang L, Zhang J, Yuan D, Xu C, Li X, Zhou D, Wang S, Zhang Q. Heterosis and polymorphisms of gene expression in an elite rice hybrid as revealed by a microarray analysis of 9198 unique ESTs. Plant Mol Biol. 2006; 62:579-91.

31. Zhai R, Feng Y, Wang H, Zhan X, Shen X, Wu W, Zhang Y, Chen D, Dai G, Yang $Z$, et al. Transcriptome analysis of rice root heterosis by RNA Seq. BMC Genomics. 2013;14:19.

32. Huang EZ, Zhang SY, Ge L, Wang L. Genome-wide transcriptome profiles of rice hybrids and their parents. Int J Mol Sci. 2014;15:20833-45.

33. Yuan H, Qin P, Hu L, Zhan SJ, Wang SF, Gao P, Li J, Jin MY, Xu ZY, Gao Q, et al. OsSPL18 controls grain weight and grain number in rice. J Genet Genomics. 2019;46:41-51.

34. Jiao Y, Wang Y, Xue D, Wang J, Yan M, Liu G, Dong G, Zeng D, Lu Z, Zhu X, et al. Regulation of OSSPL14 by OsmiR156 defines ideal plant architecture in rice. Nat Genet. 2010:42:541-4.

35. Xue W, Xing Y, Weng X, Zhao Y, Tang W, Wang L, Zhou H, Yu S, Xu C, Li X, et al. Natural variation in Ghd7 is an important regulator of heading date and yield potential in rice. Nat Genet. 2008;40:761-7.

36. Huang X, Qian Q, Liu Z, Sun H, He S, Luo D, Xia G, Chu C, Li J, Fu X. Natural variation at the DEP1 locus enhances grain yield in rice. Nat Genet. 2009;41: 494-7.

37. Li M, Tang D, Wang K, Wu X, Lu L, Yu H, Gu M, Yan C, Cheng Z. Mutations in the F-box gene LARGER PANICLE improve the panicle architecture and enhance the grain yield in rice. Plant Biotechnol J. 2011;9(9):1002-13.

38. Ashikari M, Sakakibara H, Lin S, Yamamoto T, Takashi T, Nishimura A, Angeles ER, Qian Q, Kitano H, Matsuoka M. Cytokinin oxidase regulates rice grain production. Science. 2005;309:741-5

39. Wang S, Wu K, Yuan Q, Liu X, Liu Z, Lin X, Zeng R, Zhu H, Dong G, Qian Q, et al. Control of grain size, shape and quality by OSSPL16 in rice. Nat Genet. 2012:44:950-4.

40. Wang L, Sun S, Jin J, Fu D, Yang X, Weng X, Xu C, Li X, Xiao J, Zhang Q. Coordinated regulation of vegetative and reproductive branching in rice. Proc Natl Acad Sci U S A. 2015;112:15504-9. 
41. Li S, Zhao B, Yuan D, Duan M, Qian Q, Tang L, Wang B, Liu X, Zhang J, Wang J, et al. Rice zinc finger protein DST enhances grain production through controlling Gn1a/OsCKX2 expression. Proc Natl Acad Sci U S A. 2013;110:3167-72.

42. Bai $X$, Huang $Y$, Mao D, Wen M, Zhang $L$, Xing $Y$. Regulatory role of FZP in the determination of panicle branching and spikelet formation in rice. Sci Rep. 2016;6:19022.

43. Liu D, Li SY, Wang LN, Li Q, Cui YJ, Dai XD, Zhao ZL, Chen C, Li JX, Liu ZL. Cloning and expression analysis of SiCDPK4, a gene related to heterosis in Foxtail millet [(Setaria italica (L.) P. Beauv.)]. J Plant Growth Regul. 2019;38: 513-22.

44. Huang X, Yang S, Gong J, Zhao Q, Feng Q, Zhan Q, Zhao Y, Li W, Cheng B, $X i a$ J, et al. Genomic architecture of heterosis for yield traits in rice. Nature. 2016;537:629-33.

45. Shahid MQ, Chen F, Li H, Wang S, Chen P, Lin S, Liu X, Lu Y. Double neutral genes, $S a-n$ and $S b-n$, for pollen fertility in rice to overcome indica $\times$ japonica hybrid sterility. Crop Sci. 2013;53:164-76.

46. He J, Shahid MQ, Li Y, Guo H, Cheng X, Liu X, Lu Y. Allelic interaction of $F_{1}$ pollen sterility loci and abnormal chromosome behaviour caused pollen sterility in intersubspecific autotetraploid rice hybrids. J Exp Bot. 2011;62: 4433-45.

47. Zhang L, Yu H, Ma B, Liu G, Wang J, Wang J, Gao R, Li J, Liu J, Xu J, et al. A natural tandem array alleviates epigenetic repression of IPA 1 and leads to superior yielding rice. Nat Commun. 2017:8:14789.

48. Chen L, Bian JM, Shi SL, Yu JF, Khanzada H, Wassan GM, Zhu CL, Luo X, Tong S, Yang XR, Peng XS, Yong S, Yu QY, He XP, Fu JR, Chen XR, Hu LF, Ouyang $\sqcup, \mathrm{He} H \mathrm{H}$. Genetic analysis for the grain number heterosis of a super-hybrid rice WFYT025 combination using RNA-Seq. Rice. 2018;11:37.

49. Zuo S, Kang H, Li Q, Chen Z, Zhang Y, Liu W, Wang G, Chen H, Pan X. Genome wide association analysis on genes controlling panicle traits of varieties from international rice core collection bank and its breeding utilization. Chin J Rice Sci. 2014;28:649-58.

50. Megersa A, Lee D, Park J, Koh HJ. Genetic mapping of a rice loose upper panicle mutant. Plant Breed Biotech. 2015;3(4):366-75.

51. Liu T, Li L, Zhang Y, Xu C, Li X, Xing Y. Comparison of quantitative trait loc for rice yield, panicle length and spikelet density across three connected populations. J Genet. 2011;90:377-82.

52. Marathi B, Guleria S, Mohapatra T, Parsad R, Mariappan N, Kurungara VK, Atwal SS, Prabhu KV, Singh NK, Singh AK. QTL analysis of novel genomic regions associated with yield and yield related traits in new plant type based recombinant inbred lines of rice (Oryza sativa L.). BMC Plant Biol. 2012;12:137.

53. Yao XY, Li Q, Liu J, Jiang SK, Yang SL, Wang JY, Xu ZJ. Dissection of QTLs for plant height and panicle length traits in rice under different environment. Sci Agric Sin. 2015;48:407-14.

54. Zhang L, Wang J, Wang J, Wang L, Ma B, Zeng L, Qi Y, Li Q, He Z. Quantitative trait locus analysis and fine mapping of the QPL6 locus for panicle length in rice. Theor Appl Genet. 2015;128:1151-61.

55. Ishii T, Numaguchi K, Miura K, Yoshida K, Thanh PT, Htun TM, Yamasaki M, Komeda N, Matsumoto T, Terauchi R, et al. OsLG1 regulates a closed panicle trait in domesticated rice. Nat Genet. 2013;45:462-5.

56. Cota-Sanchez JH, Remarchuk K, Ubayasena K. Ready-to-use DNA extracted with a CTAB method adapted for herbarium specimens and mucilaginous plant tissue. Plant Mol Biol Report. 2006;24:161-7.

57. Bai H, Cao Y, Quan J, Dong L, Li Z, Zhu Y, Zhu L, Dong Z, Li D. Identifying the genome-wide sequence variations and developing new molecular markers for genetics research by re-sequencing a landrace cultivar of Foxtail Millet. PLoS One. 2013;8(9):e73514

58. Kim D, Pertea G, Trapnell C, Pimentel H, Kelley R, Salzberg SL. TopHat2: accurate alignment of transcriptomes in the presence of insertions, deletions and gene fusions. Genome Biol. 2013;14(4):R36.

59. Trapnell C, Williams BA, Pertea G, Mortazavi A, Kwan G, van Baren MJ, Salzberg SL, Wold BJ, Pachter L. Transcript assembly and quantification by RNA-Seq reveals unannotated transcripts and isoform switching during cell differentiation. Nat Biotechnol. 2010;28:511-5.

60. Youens-Clark K, Buckler E, Casstevens T, Chen C, Declerck G, Derwent P, Dharmawardhana P, Jaiswal P, Kersey P, Karthikeyan AS, et al. Gramene database in 2010: updates and extensions. Nucleic Acids Res. 2011;39: D1085-94.

61. Livak KJ, Schmittgen TD. Analysis of relative gene expression data using real-time quantitative PCR and the $2^{-\Delta \Delta C T}$ method. Methods. 2001;25:402-8.

\section{Publisher's Note}

Springer Nature remains neutral with regard to jurisdictional claims in published maps and institutional affiliations.

\section{Ready to submit your research? Choose BMC and benefit from:}

- fast, convenient online submission

- thorough peer review by experienced researchers in your field

- rapid publication on acceptance

- support for research data, including large and complex data types

- gold Open Access which fosters wider collaboration and increased citations

- maximum visibility for your research: over $100 \mathrm{M}$ website views per year

At BMC, research is always in progress.

Learn more biomedcentral.com/submissions 